\title{
Alteration effect on petrophysical properties of reservoirs rocks by drilling fluid emulsifiers
}

\author{
Zineb Bazzine $^{1} \odot \cdot$ Abdelmadjid Dobbi $^{1} \cdot$ Hamid Lebtahi $^{1} \cdot$ Ahmed Ali Zerrouki $^{1}$
}

Received: 26 February 2021 / Accepted: 15 July 2021 / Published online: 24 July 2021

(c) The Author(s) 2021

\begin{abstract}
Surfactants formulated into oil-based mud can adsorb to pore surfaces causing changes in rock wettability, which are widely believed to impair formation permeability when oil-based mud invades the near-wellbore region. In the present study, the effects of oil-based mud with Versawet and Versacoat surfactants, on the petrophysical properties and wettability of drilling cutting samples from sandstone reservoirs were investigated through relative permeability, wettability index, and adsorption measurements at standard conditions in a micromodel device. The X-ray analysis and flame photometer were used to characterize the drilling cuttings samples, and the functional groups of surfactants were identified by the infrared spectroscopy. Relative permeability was studied using the unsteady state method, and the wettability index was measured by the Amott method after the aging with drilling formulation for 24 to $720 \mathrm{~h}$ and then the adsorption behavior of surfactants using Langmuir isotherm. The results show that drilling cutting is mainly composed of quartz $71.9 \%$. Surfactant in oil-based mud reduces permeability and causes a change in wettability to a more oil-wet state, and these effects become more pronounced as the contact period with the surfactant increases. The wettability of a reservoir rock was altered due to surfactant adsorption and the formation of a hydrophobic layer on the surface of drilling cutting samples. The adsorption and retention of polar part of the surfactants $-\mathrm{NH}_{2}$ for Versawet and $-\mathrm{COOH}$ for Versacoat on the silanol groups and the calcium atoms included in the structure of the reservoir rocks. They are the key interactions in the wettability alteration process.
\end{abstract}

Keywords Drilling cuttings $\cdot$ Relative permeability $\cdot$ Wettability alteration $\cdot$ Amott method $\cdot$ Oil-based mud $\cdot$ Adsorption

\section{Introduction}

Surfactants formulated into the emulsifier additives, which are used to stabilize oil-based drilling fluids, and as wetting agents can change the wettability of water-wet sandstones to a preferentially oil-wet state. Changes in wettability caused by adsorption of surfactant molecules to pore surfaces could be part of formation damage (Solling et al., 2021) by altering the oil relative permeability (Kro) and residual oil saturation (Sor) of the reservoir invaded region near a producing well. In this case, an increase in the water cut could be observed just after the completion of the well. (Ibrahim et al., 2017) are considered that selecting the right composition of

Zineb Bazzine

Bazzine27@Gmail.Com

Faculty of Hydrocarbons, Renewable Energies, and Earth and Universe Sciences, Kasdi Merbah University of Ouargla, 30000 Ouargla, Algeria drilling fluid can be a key factor in minimizing formation damage and obtaining desired productivity index.

Research on reservoir formation damage mechanisms and their prevention is increasingly widespread (Civan, 2016; Mohammadi \& Mahani, 2020) and must therefore be understood as a priority in order to guide the development and the design of reservoir protection measures (He, 2021).

According to Zhao et al (2019), the main formation damage mechanisms that could be expected in the field are fluid-fluid incompatibilities, rock-fluid incompatibilities, solids invasion, phase trapping or blocking, chemical adsorption or wettability alteration, fines migration, and biologic activity.

Several studies have been performed on the formation damage mechanisms by surfactant in oil-based muds (Bishop, 1997; Menezes, 1989; Civan, 2007; Xu et al., 2016; Hursan et al., 2018), and on the evaluation of the degree to which wettability alteration is affected by drilling fluid composition (Abdollah-Pour et al., 2016). 
Most of these studies focused on the measurement of contact angles (Lei et al., 2017). Fluid displacement tests involving forced displacement and spontaneous imbibition have also been used to quantify wettability alteration caused by drilling fluids (Amott, 1959; Chen et al., 2006).

Result from core tests indicates that wettability alteration and permeability impairment can be influenced substantially by the type and concentration of surfactant in oil-based drilling fluid. Therefore, surfactant adsorption in oil reservoirs as a mechanism of formation damage is driven by various factors such as surface charge of reservoir, type of surfactant, temperature, $\mathrm{pH}$ and salinity of formation water (Kumar \& Mandal, 2019).

Amirmoshiri et al (2020) mentioned that electrostatic attraction, van der Waals interactions between the nonpolar surfactant chains, hydrophobic tail-solid interactions, chemisorption, surface precipitation, hydrogen bonding, and adsorption via ion exchange are, however, the different mechanisms for surfactant adsorption on the rock surface. In addition, surfactant retention in porous media occurs according to three essential mechanisms: precipitation, adsorption and phase trapping (Belhaj et al., 2020).

In the literature, illustrating a curve between the amounts of adsorbate adsorbed on the adsorbent and the concentration represent isothermal model. During the last decade, a large variety of isotherm models such as Langmuir, Freundlich, Dubinin-Radushkevich, Temkin, Toth and various other isotherms (Al-Ghouti \& Da' ana, 2020).

The purpose of the work described in this paper was to assess the effect of surfactant adsorption on petrophysical parameters as a mechanism of formation damage. Wettability and relative permeability changes at connate water saturation caused by oil-based mud emulsifiers have been measured. The experiments specifically investigate surfactant adsorption to pore surfaces of unconsolidated sandstones (drilling cutting samples were used). Initially, formulation of Versawet and Versacoat commercial emulsifier commonly used in oil-based drilling fluids in Berkine field was used to simulate invading mud filtrate. The amount of surfactant retained in unconsolidated sandstone samples after contacting emulsifier formulation was estimated from the adsorption study based on Langmuir isotherm. In later experiments, wettability and relative permeability changes induced by surfactant in prepared oil-based mud formulation were investigated through fabricated micromodels as a function of time. As results, the effect of commercial surfactant on the wettability and relative permeability of drilling cutting sandstone samples was obtained, and a novel mechanism of formation damage by emulsifiers in oil-based muds was established to assess the effect of surfactant adsorption on petrophysical parameters.

\section{Materials and experimental methods}

\section{Drilling cutting}

Experiments were carried out on drilling cutting as a porous medium from an Algerian oil reservoir in the Berkine region. Samples were taken from a depth of 4727 to $4732 \mathrm{~m}$. The average porosity of samples is $17.54 \%$.

Our choice focused for the drilling cuttings because they present similar characteristics and surface chemistry to sandstones reservoir rocks.

\section{Samples preparation and cleaning}

The American Petroleum Institute RP-40 standards were used as a guide (McPhee et al., 2015). The drilling cutting samples were first cleaned with toluene for $24 \mathrm{~h}$ and then were rinsed with distilled water to remove the residual fluid.

The cleaned samples were dried in a vacuum oven at $105{ }^{\circ} \mathrm{C}$ for one day to remove the used solvents in the cleaning process.

Drilling cuttings were powdered (crushed) with Fritsch Pulverisette 2 to obtain uniformly powdered samples. Then sieved with vibratory sieve shaker As 200 Control. After studying the grain size distributions of the powder, a fraction collected in the range of $(0.1-0.5) \mathrm{mm}$ was used in the experiments.

The results of the grain size analysis of powdered drilling cutting are presented in Fig. 1. The X-ray analysis of samples was performed by Seifert XRD 3003 TT X-ray diffraction system. The XRD pattern of the samples in the range of $10^{\circ}$ to $60^{\circ}$ for $2 \theta$ was measured to determine the mineralogical composition of samples. The X-ray diffractometer (Fig. 2) indicates that samples are mainly composed of quartz (71.9\%), with some impurities that consist of dolomite $(12.2 \%)$, calcite $(2.5 \%)$ and clay minerals kaolinite (11\%), chlorite (2.3\%).

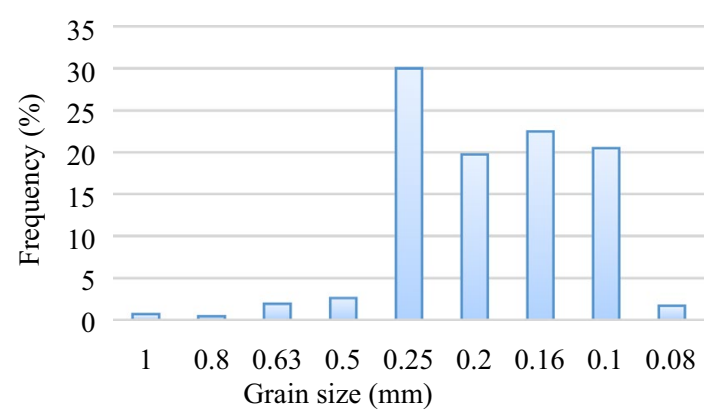

Fig.1 Histogram representation of grain size distribution of powdered drilling cutting samples 


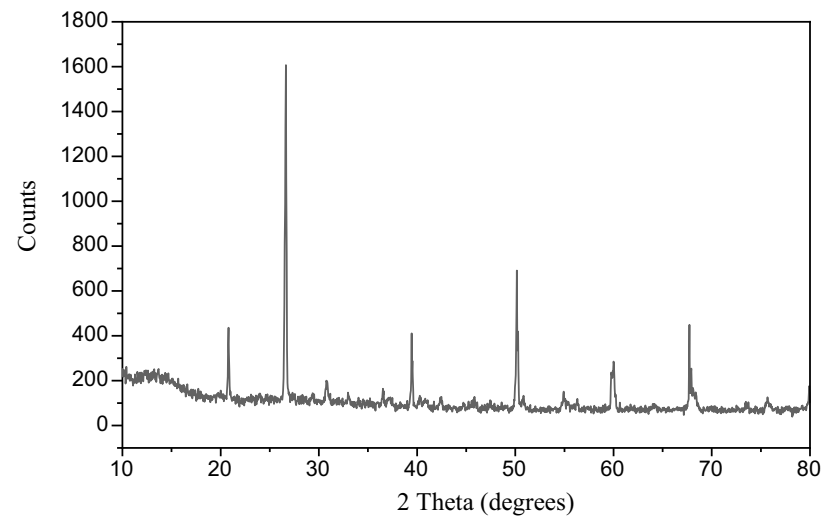

Fig. 2 The X-ray diffraction image of drilling cutting sample

Table 1 Properties of gasoil (Bergane \& Hammadi, 2020)

\begin{tabular}{ll}
\hline Density at $15^{\circ} \mathrm{C}$ & $0.828 \mathrm{~g} / \mathrm{cm}^{3}$ \\
\hline Dynamic viscosity at $20{ }^{\circ} \mathrm{C}$ & $5.6 \mathrm{mPa} \mathrm{s}$ \\
Surface tension at $20^{\circ} \mathrm{C}$ & $30.5 \mathrm{mN} / \mathrm{m}$ \\
Flash point & $88^{\circ} \mathrm{C}$ \\
Pour point & $-14{ }^{\circ} \mathrm{C}$ \\
Initial boiling point & $152{ }^{\circ} \mathrm{C}$ \\
Final boiling point & $320^{\circ} \mathrm{C}$
\end{tabular}

\section{Flame Photometer}

Flame photometer analysis is that auxiliary measurement was performed to assess the calcium content in the drilling cutting samples used by Jenway Pfp7. $1 \mathrm{~g}$ of powdered sample was dissolved in HCL in a $50 \mathrm{ml}$ volumetric flask. The standard curve of calcium concentration against intensity was plotted, from the recorded reading and the calibration graph, the samples concentration is $0.0655 \mathrm{~g}$ of calcium $(6.55 \%)$.

\section{Gasoil}

The used oil is gasoil, which is acquired by Naftal Company. The properties of gasoil are shown in Table 1 .

\section{Surfactants}

Two different commercial emulsifiers (surfactants) offered by MI-SWACO companies were used in our tests: Versacoat is a non-ionic surfactant that serves as an emulsifier and wetting agent. Versawet is a cationic surfactant (organic) that serves as a concentrated and powerful oil-wetting agent
Table 2 Physical properties of Versacoat and Versawet

\begin{tabular}{lcc}
\hline Physical properties & Versawet & Versacoat \\
\hline Appearance & Dark brown, viscous & Dark amber \\
& liquid & \\
Specific gravity & $0.93-0.98$ & $0.90-0.97$ \\
Flash point $\left({ }^{\circ} \mathrm{C}\right)$ & 93.3 & $28{ }^{\circ} \mathrm{C}$ \\
Pour point $\left({ }^{\circ} \mathrm{C}\right)$ & 6.7 & -28.9 \\
Density at $20^{\circ} \mathrm{C}\left(\mathrm{g} / \mathrm{cm}^{3}\right)$ & 0.95 & 0.91 \\
Surface tension $(\mathrm{mN} / \mathrm{m})$ & 42.9 & 35.9 \\
$\mathrm{CMC}(\mathrm{M})$ & $2.97 .10^{-3}$ & $7.97 .10^{-5}$ \\
\hline
\end{tabular}
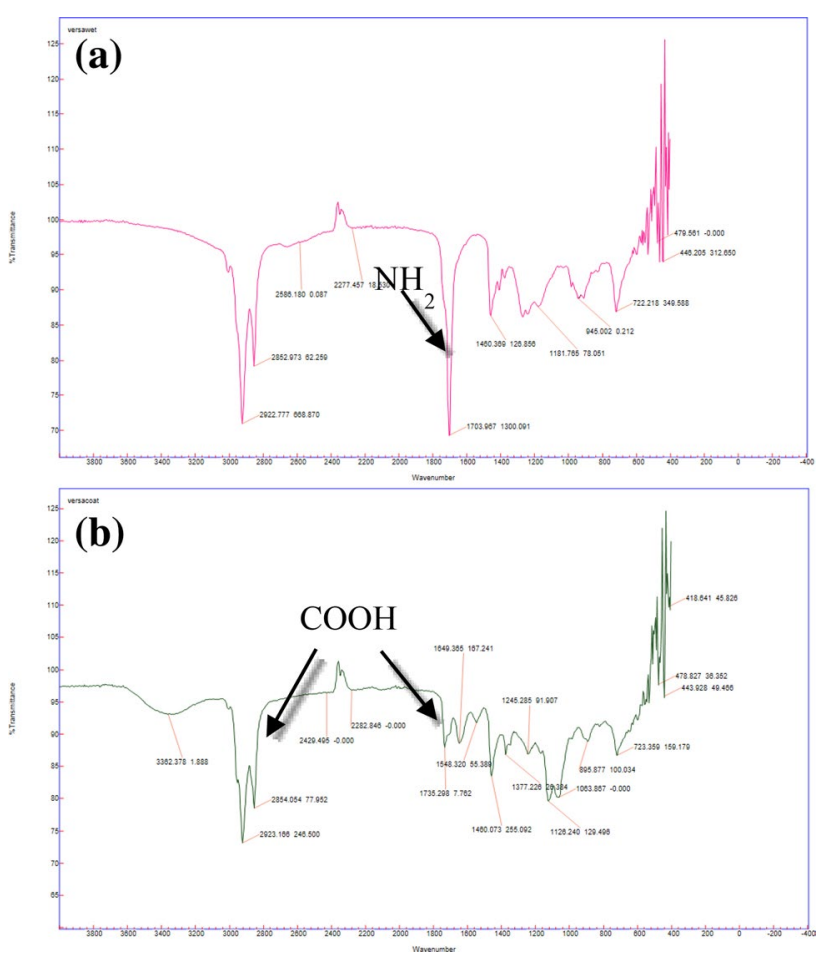

Fig. 3 FTIR spectrum of surfactants $\mathbf{a}$ Versawet and $\mathbf{b}$ Versacoat

for oil-based mud. Table 2 presents chemical and physical properties of the used surfactants.

The infrared spectroscopic measurement of surfactants was obtained using an Agilent Technologies Carry 660FTIR spectrometer at $30{ }^{\circ} \mathrm{C}$. The spectrum was collected over the spectral range of $4000-400 \mathrm{~cm}^{-1}$. The IR spectrum of surfactants is shown in Fig. 3.

The wavenumbers at 1460.073 and $1460.369 \mathrm{~cm}^{-1}$ are attributed to the stretching vibrations of methylene scissoring vibrational. The wavenumbers at 2922.777, 2852.01, 2923.166 and $2854.054 \mathrm{~cm}^{-1}$ are attributed to the asymmetric and symmetric $\mathrm{CH}_{3} / \mathrm{CH}_{2}$ stretching vibrational frequencies, respectively (Viana et al., 2012). 
Table 3 Properties of used lime

\begin{tabular}{lc}
\hline Property & Value \\
\hline Sp. Gr & 2.2 \\
Molecular weight & 74.1 \\
Solubility at 100_C (g lime/100 g water) & 0.077 \\
Solubility at 20_C (g lime/100 g water) & 0.173 \\
PH & 12.4 \\
\hline
\end{tabular}

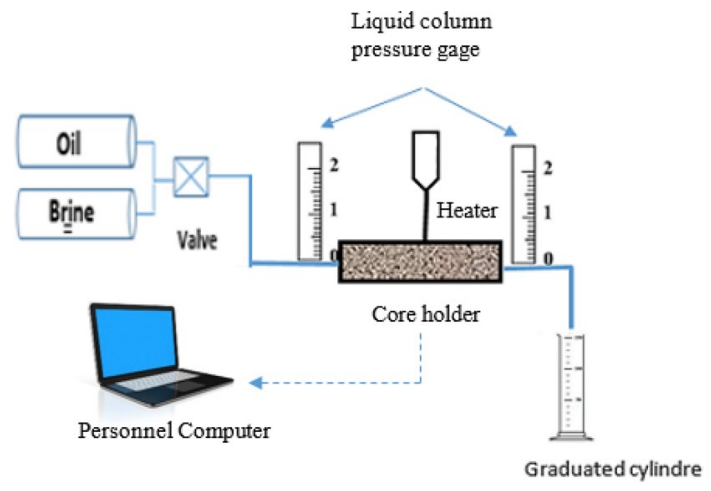

Fig. 4 Micromodel of experimental setup for the displacement tests (experiments were performed at $40{ }^{\circ} \mathrm{C}, 5.101 \mathrm{kPa}$ )

The wavenumbers located at 1703.967 are attributed to ammonium amines quaternaries $-\mathrm{NH}_{2}$ (Kowalczyk, 2008) Fig. 3a.

The wavenumber at $1735.298,2854.054$ and $2923.166 \mathrm{~cm}^{-1}$ corresponds to carboxyl group $(\mathrm{COOH})$ $\mathrm{C}-\mathrm{O}$ and $\mathrm{O}-\mathrm{H}$, respectively Fig. $3 \mathrm{~b}$.

\section{Brine}

A sodium chloride was used to prepare synthetic brine solution. $320 \mathrm{~g}$ of $\mathrm{NaCl}$ was dissolved in $1000 \mathrm{ml}$ of distilled water to obtain a saturated brine solution, which is used throughout all experiments.

\section{Lime}

It is a powder and an inorganic compound $\mathrm{Ca}(\mathrm{OH})_{2}$. It is used as a surfactant-activating agent and hydrophilic-lipophilic balance 'HLB' reducer to obtain reverse emulsion with a concentration of $19.92 \mathrm{~g} / \mathrm{l}$. Table 3 shows the property of used lime.

\section{Experimental procedures}

In this work, experiments were performed in a micromodel (Fig. 4) involving, transfer vessels, cylindrical sample holder with approximately $65 \mathrm{~mm}$ length, $35 \mathrm{~mm}$ radius, outlet/ input pressure gauge, thermometer and graduated cylinder to receive the fluid. The differential pressure was obtained based on direct reading of elevation.

Before running each test, the micromodel was cleaned to assure no oil is remained after previous run. Toluene and distilled water were injected into the micromodel for several cycles during the cleaning process;

\section{Fluids formulation}

In this study, we propose the formulation described in Table 4 , and these formulations are prepared by successively adding the products under agitation $(800 \mathrm{rpm})$ carried out by an AREC magnetic stirrer for $1 \mathrm{~h}$ at $25^{\circ} \mathrm{C}$, with a density of $0.850 \mathrm{~g} / \mathrm{cm} 3$. When mixing the formulations, the following order of addition is followed:

- Gasoil

- Surfactant

- Lime

\section{Relatives permeability measurement}

In this study, the steady state method is used to measure the oil - water relative permeability in the experiments. The steady state method is one of the desired methods in the literature and considered more accurate and reliable. (Nazari Moghaddam \& Jamiolahmady, 2019).

Table 4 Formulation used in the experiment

\begin{tabular}{lclllc}
\hline Product & $\begin{array}{l}\text { Formulation 1 } \\
(\mathrm{VWF})\end{array}$ & $\begin{array}{l}\text { Formulation 2 } \\
(\mathrm{VCF})\end{array}$ & $\begin{array}{l}\text { Formulation 3 } \\
(\mathrm{WVF})\end{array}$ & $\begin{array}{l}\text { Time of agita- } \\
\text { tion }(\mathrm{h})\end{array}$ & $\begin{array}{l}\text { Speed of } \\
\text { agitation } \\
(\mathrm{rpm})\end{array}$ \\
\hline Gasoil $(\mathrm{l})$ & 1 & 1 & 1 & - & - \\
Versawet $(\mathrm{g} / \mathrm{l})$ & 2.5 & - & 2.5 & 1 & 800 \\
Versacoat $(\mathrm{g} / \mathrm{l})$ & - & 5 & 5 & 1 & 800 \\
Lime $(\mathrm{g} / \mathrm{l})$ & 19.92 & 19.92 & 19.92 & 1 & 800 \\
\hline
\end{tabular}


The experiment is conducted at $40{ }^{\circ} \mathrm{C}$, and under the pressure of $5.101 \mathrm{kPa}$ in the micromodels (Fig. 4).

The key point of the experiment is to obtain the relative permeability curve after the reaction of the samples with the different formulation during $24 \mathrm{~h}$.

The relative permeability experiment has the following steps:

The first step would be to saturate the sample $100 \%$ with brine to measure the absolute permeability.

Then, gasoil is injected to drain the brine out of the rock to reach the irreducible water saturation. (This condition represents the initial reservoir condition.)

After that, both gasoil and brine are injected simultaneously.

After the system reaches the steady state and the data are recorded, generalized Darcy's law (Darcy's law for singlephase fluid flow in porous media is extended to two-phase flow) is used to determine water-oil relative permeability according to Eqs. 1 and 2. The average saturation in the sample was calculated directly by the volumes of the injected and product fluids measured.

The empirical model of Darcy in horizontal flow is written:

$\mathrm{Q}_{o}=\frac{\text { Kro.K.A }}{\mu o \cdot \mathrm{L}} \cdot \Delta \mathrm{P}_{\mathrm{o}}$

$\mathrm{Qw}=\frac{\mathrm{Krw} \cdot \mathrm{K} \cdot \mathrm{A}}{\mu w \cdot \mathrm{L}} \cdot \Delta \mathrm{P}_{w}$

where $\mathrm{Q}_{\mathrm{o}}$ is volumetric oil flow rate $\left(\mathrm{cm}^{3} / \mathrm{s}\right), \mathrm{Q}_{\mathrm{w}}$ is volumetric water flow rate $\left(\mathrm{cm}^{3} / \mathrm{s}\right), \mathrm{K}_{\mathrm{rw}}$ is relative permeability of water, $\mathrm{K}_{\mathrm{ro}}$ is relative permeability of oil, $\mathrm{A}$ is cross-section area of the sample $\left(\mathrm{cm}^{2}\right), \Delta \mathrm{P}_{\mathrm{w}}$ is $\Delta \mathrm{P}$ of water (atm), $\Delta \mathrm{P}_{\mathrm{o}}$ is $\Delta \mathrm{P}$ of oil (atm), $\mathrm{L}$ is sample length $(\mathrm{cm}), \mu_{\mathrm{w}}$ is water viscosity $(\mathrm{atm} / \mathrm{s}), \mu_{\mathrm{o}}$ is oil viscosity $(\mathrm{atm} / \mathrm{s}) . \mathrm{K}$ is the absolute permeability (D).

\section{Wettability tests (Amott method)}

The wettability index was evaluated by preparing 26 samples.

Experiments started with saturation of all porous media with saturated brine that was used throughout all experiments and then is flooded by gasoil until no more water is produced.

This process aims to establish initial condition of samples. Then, powdered samples in core holder were aged in the formulations prepared (VWF VCF WCF) at $40{ }^{\circ} \mathrm{C}$ for $24 \mathrm{~h}, 46 \mathrm{~h}, 72 \mathrm{~h}, 168 \mathrm{~h}$ and $720 \mathrm{~h}$.

Finally, after aging, the following experimental protocol is adopted:
- The samples were submerged in brine in Amott cells and the spontaneously produced oil was recorded after $20 \mathrm{~h}$ (volume $\mathrm{V}_{1}$ = gasoil spontaneously displaced by brine)

- The brine is forced into the sample by injection at a constant rate (volume $\mathrm{V}_{2}=$ gasoil displaced by brine)

- The sample is immersed into gasoil (volume $\mathrm{V}_{3}=$ brine spontaneously displaced by gasoil)

- Then gasoil is forced into the samples by injection at a constant rate (volume $\mathrm{V}_{4}=$ water displaced by oil).

The Amott cell used for spontaneous imbibition (Fig. 5) is funnel-shaped lucite tubes calibrated so that the volume of fluid released can be read easily.

The sample holders were made of PVC "polyvinyl chloride" for powder samples, then it was perforated from all sides and is placed at the middle of the lower part of Amott cell.

The Amott wettability index has been calculated according to Eq. 3:

$W I=I w-I o=\frac{V 1}{V 1+V 2}-\frac{V 3}{V 3+V 4}$

where $I_{o}$ is the oil wettability index and $I_{w}$ is the water wettability index.

\section{Interfacial tension measuring}

The drop-weight method is an accurate yet simple technique for determining surface tension (Lee et al., 2008; Butt et al., 2013). This method was fist time described by Tate in 1864 who formed an equation, which is now called the Tate's law:

$\mathrm{mg}=2 \pi r \gamma$

where $m$ is the drop weight (to get a precise measure, this is done for a number of 15 drops and this number divides the total weight), $g$ the acceleration of gravity, $r$ is the external

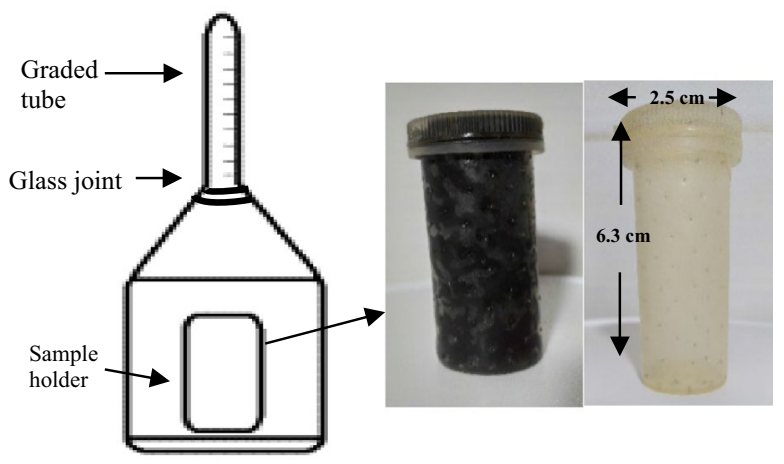

Fig. 5 Schematic drawing of an Amott imbibition cell with PVC perforated sample holder fill (left) and empty (right)

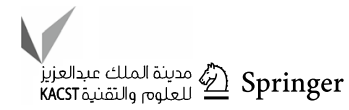




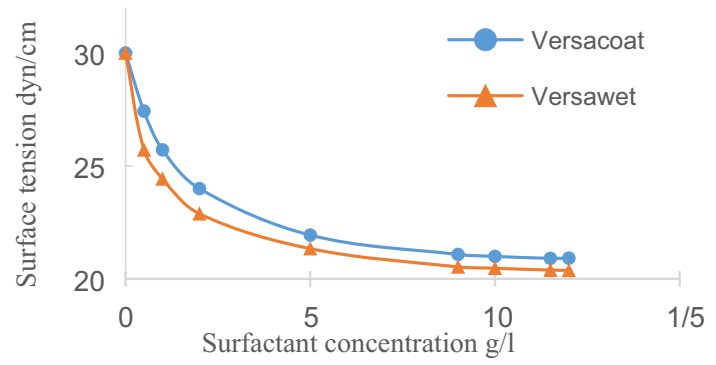

Fig. 6 Calibration curve: surface tension plot of surfactants with varying concentration

radius of the capillary, and $\gamma$ is the surface tension of the liquid.

The surface tension with different concentrations of surfactants in the gasoil formulations was measured to plotting the calibration curve of Versawet and Versacaot (Fig. 6).

\section{Adsorption measurements}

The adsorption study involves interaction of VCF and VWF formulations with powdered samples leading to loss of surfactant due to adsorption. It was conducted by mixing $1 \mathrm{~g}$ of powdered rock sample with $50 \mathrm{ml}$ of gasoil formulation with different concentrations of the surfactants.

The solutions and powdered samples were aged for $24 \mathrm{~h}$ and then mixed at $30^{\circ} \mathrm{C}$. The floating liquid was collected after centrifugation for $15 \mathrm{~min}$ at $5000 \mathrm{rpm}$. The unknown concentration of surfactant in the supernatant solution was determined using the calibration curve shown in Fig. 6. The adsorption density was calculated using the initial and final bulk concentrations of surfactant as (Kumar \& Mandal, 2019):

$q e=\frac{(\mathrm{Ci}-\mathrm{Ce}) \mathrm{V}}{\mathrm{m}}$

where $q_{e}$ is the adsorption density $(\mathrm{mg} / \mathrm{g}), \mathrm{C}_{\mathrm{i}}$ is the initial concentration of the surfactant $(\mathrm{mg} / \mathrm{l}), \mathrm{C}_{\mathrm{e}}$ is the equilibrium concentration of the surfactant $(\mathrm{mg} / \mathrm{l}), \mathrm{V}$ is the volume of the surfactant solution (L) and $\mathrm{m}$ is the mass of the powdered sample $(\mathrm{g})$.

The amount of surfactant adsorbed per gram of cutting was then calculated at different surfactant concentrations and a Langmuir isotherm was used to model the adsorption data. The equilibrium concentration of surfactant (Ce) and adsorption typographical error density of surfactant (qe) obtained after adsorption studies were fitted to the isotherm equation of the Langmuir model and it was transformed into its linear form Eq. 6. To assess the adsorption

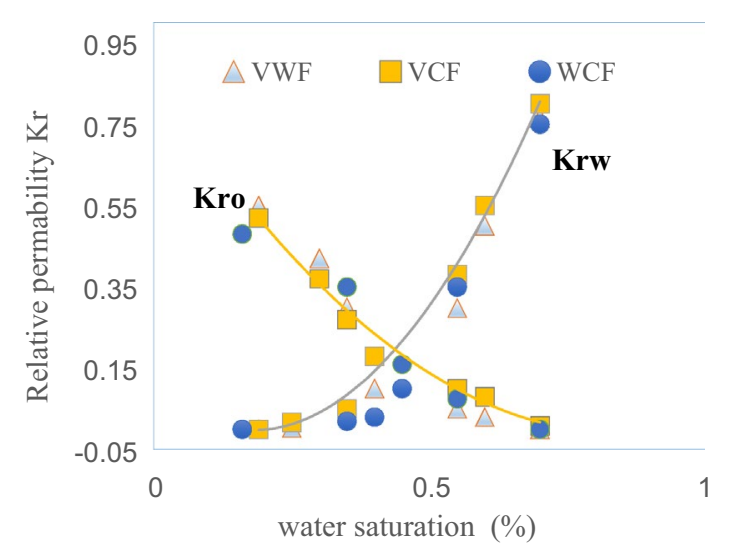

Fig. 7 Relative permeability as a function of the liquid saturation

behaviour of surfactants on the surfaces of drilling cuttings samples (Ayub et al., 2020).

$\frac{1}{q e}=\frac{1}{\mathrm{KL} \cdot q \max } \cdot \frac{1}{\mathrm{Ce}}+\frac{1}{\mathrm{qmax}}$

where $\mathrm{q}_{\max }$ represents the maximum adsorption capacity $(\mathrm{mg} / \mathrm{g})$ and $\mathrm{K}_{\mathrm{L}}(\mathrm{l} / \mathrm{mg})$ is the Langmuir's isotherm constant.

\section{Results and discussion}

\section{Result of relative permeability measurements}

It can be seen from the oil-water relative permeability curves shown in Fig. 7 that the relative permeability of brine increases rapidly, the relative permeability of gasoil decreases. The gasoil relative permeability has been low while the brine will have higher mobility when compared to gasoil.

The brine relative permeability end-point will be at a maximum of 0.75 , and the crossover will occur at a water saturation of $<0.5$.

According to (Craig, 1971), this scenario indicates that the system is oil-wet, and the relative permeability curves act in the opposite manner when compared to water-wet systems. The gasoil occupies smaller flow channels (trapped in the centers of the small pore) and coats the walls of the larger ones, causing a higher brine relative permeability.

The brine, on the other hand, will fill the large pores, giving low flow conductance to gasoil.

The relative permeability is dependent upon both the fluid saturation and the distribution of the various fluids in the interstices of the porous network. The interaction of Versacoat and Versawet surfactants in the formulation contributing to the permeability impairments observed by the interactions with the porous medium and the adsorption to 
Fig. 8 Figure illustrated phase trapping of oil due to bypassing effects in pores that divide into two branches with different diameters (a), snap-off effect occurs in pores with large diameter (b) and Jamin effect (c)

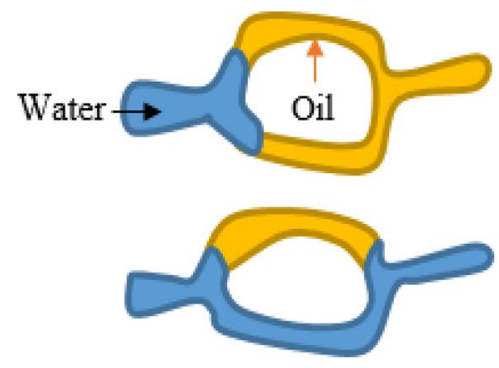

(a)

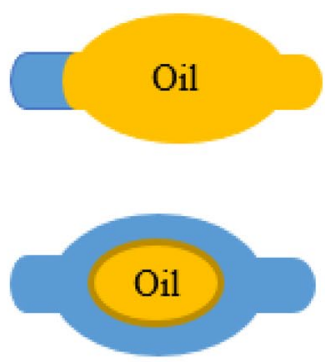

(b)

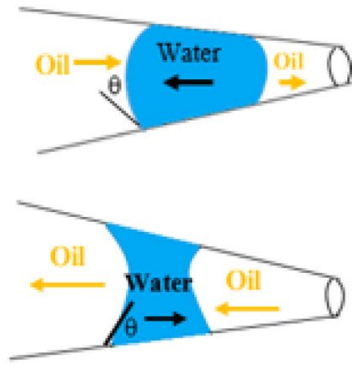

(c) pore wails altering the wettability of the system. This alteration is explained at the pore scale by the Jamin effect, phase trapping of oil due to snap-off, and bypassing by the wetting phase (see Fig. 8) (Liu et al., 2021). This is why the oil reservoir will be oil production poorly (productivity indexes drop), with the rapid increase in water cut, and high residual oil saturation, after formation damage by oil-based mud.

\section{Wettability index measurement}

The results displayed in Table 5 are also plotted in Fig. 9 (Amott wettability index, against aging time) for better visualization of the data. Results clearly show that the Amott wettability index decries with time from 0.354 to 0.010 for the samples aged with VWF, -0.040 for VCF and -0.402 for WCF. In the initial state, the Amott index is 0.300 this is demonstrate that all the samples tested departed from a water-wet condition.

All the systems with aging times of $720 \mathrm{~h}$ or less gave Amott wettability indexes less than 0.3. Systems with Amott indexes of -0.402 are oil-wet and in the range of -0.04 , 0.01 are usually classified as intermediate to neutral oilwet. After the aged with surfactant, the wettability of all samples was altered by the adsorption of polar compounds of surfactants molecules on the surface of samples forming a hydrophobic film (surfactant adsorption on drilling cuttings surface) due to various attractions such as electrostatic pairing between the charged head of surfactant and charged surface. For the mixture of surfactants WCF, the alterations are more than individual surfactants VWF and VCF. This difference in surfactant behavior reflects a difference in the adsorption sites of these surfactants in a porous medium Fig. 10 and explained by the synergistic effect between the surfactants (Bagheri \& Khalili, 2017), generated by the molecular interactions between the nonpolar parts of Versawet and Versacoat and therefore the increase in wettability alteration.

\section{Mechanism of surfactant adsorption on the surface of drilling cutting}

The adsorption of surfactants on drilling cutting was measured by recording the surfactant concentrations before and after equilibrium with drilling cutting. The adsorbance of surfactant equilibrated with cutting was analyzed and compared to the calibration curve. Adsorption behavior of surfactant on cutting samples is shown in Fig. 11 a, and it can be seen from the figure that: the amount of surfactant adsorbed on the drilling cutting samples increases with increase in the equilibrium concentration of the surfactants in the formulation. The adsorption process of Versawet and Versacoat carried out according to the Langmuir isotherm is localized monolayer adsorption (see Fig. 11 b). The parameters of the Langmuir model obtained are shown in Table 6. Versawet emulsifier adsorbs more rapidly than Versacoat with a maximum adsorption capacity of $0.9223 \mathrm{mg} / \mathrm{g}$.

According to the results of FITR, Versawet is a cationic wetting agent with quaternary ammonium cations $-\mathrm{NH}_{2}$.

Versawet ammonium is fixed in particular on the negative quartz silanole $\mathrm{Sio}_{2}$ sites of the drilling cuttings samples (Fig. 12 a). Versacoat surfactant contains a carboxylic group $\mathrm{COOH}$, and its activation is carried out by the existence of lime. The results of flame photometer confirm the existence of calcium atoms in the cutting samples.

According to the rule of selective adsorption of Panetta-faience Versacoat, calcium molecules are selectively adsorbed on the surface of drilling cuttings (Fig. 12 b).

\section{Conclusion}

The use of oil-based muds in petroleum formations is in some cases accompanied by an alteration of the petrophysical properties of the reservoir rocks. This alteration is the result of the adsorption of oil-based mud surfactant. The change of polarity of the reservoir rock will induce a modification of oil relative permeability Kro and residual oil saturation Sor. In this case, a drop in oil productivity and an

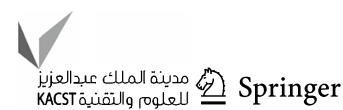




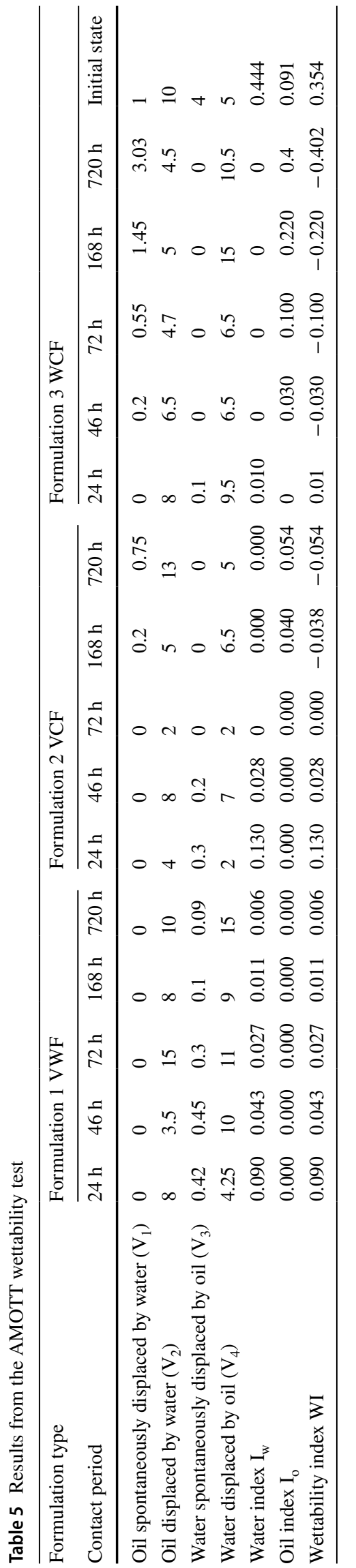

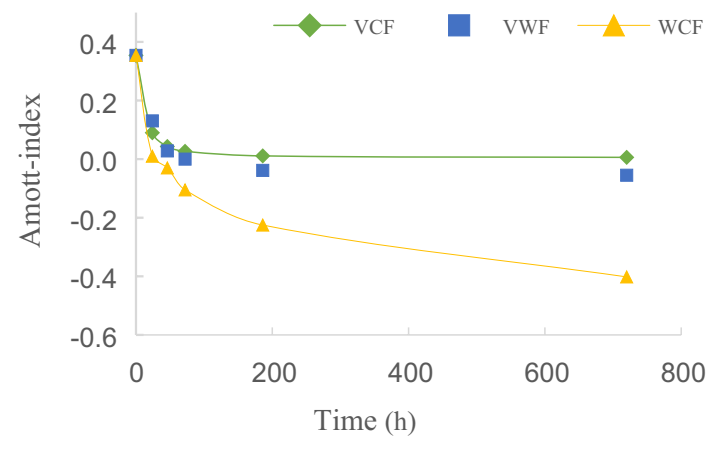

Fig. 9 Amott wettability index against time

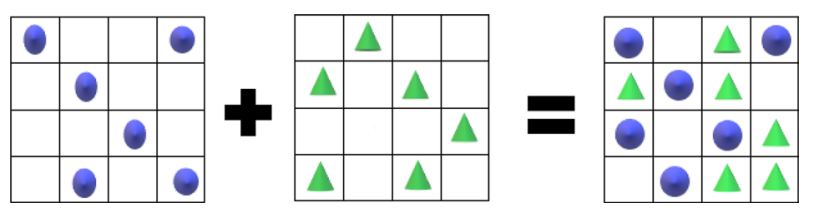

Fig. 10 Schematic showing adsorption sites to clarifying the basic assumptions: occupied sites with Versawet (blue) and occupied sites with Versacoat (green)

increase in water cut are observed just after the completion of production well.

In this study, the alteration of petrophysical properties of sandstone reservoir rocks due to the adsorption of oil-based mud surfactants has been systematically investigated.

Based on the experimental results, the following conclusions can be made:

- The drilling cutting samples from sandstone reservoir formation are characterized by the predominance of quartz $71.9 \%$ with clay mineral, dolomite and calcite content. Drilling cutting samples effectively evaluate relative permeability and wettability alteration caused by surfactants in oil-based mud; the results are in qualitative agreement with the core sample observations.

- Rock-fluid incompatibilities occur due to the interaction of Versawet and Versacoat surfactant with the formation leading to permeability impairment with a maximum water relative permeability end point of 0.75 and a rapid decrease in oil relative permeability.

- Versawet and Versacoat emulsifiers in oil-based mud greatly changed the wettability of drilling cutting surface from water-wet (Amott index in initial state of 0.354) to oil-wet with the increase in contact period. The most dramatic effects were those found for the samples contaminated with both surfactant with Amott index of - 0402 . The alteration of wettability caused by Versawet and Versacoat separately was not as large as that with the mixture of surfactants. 

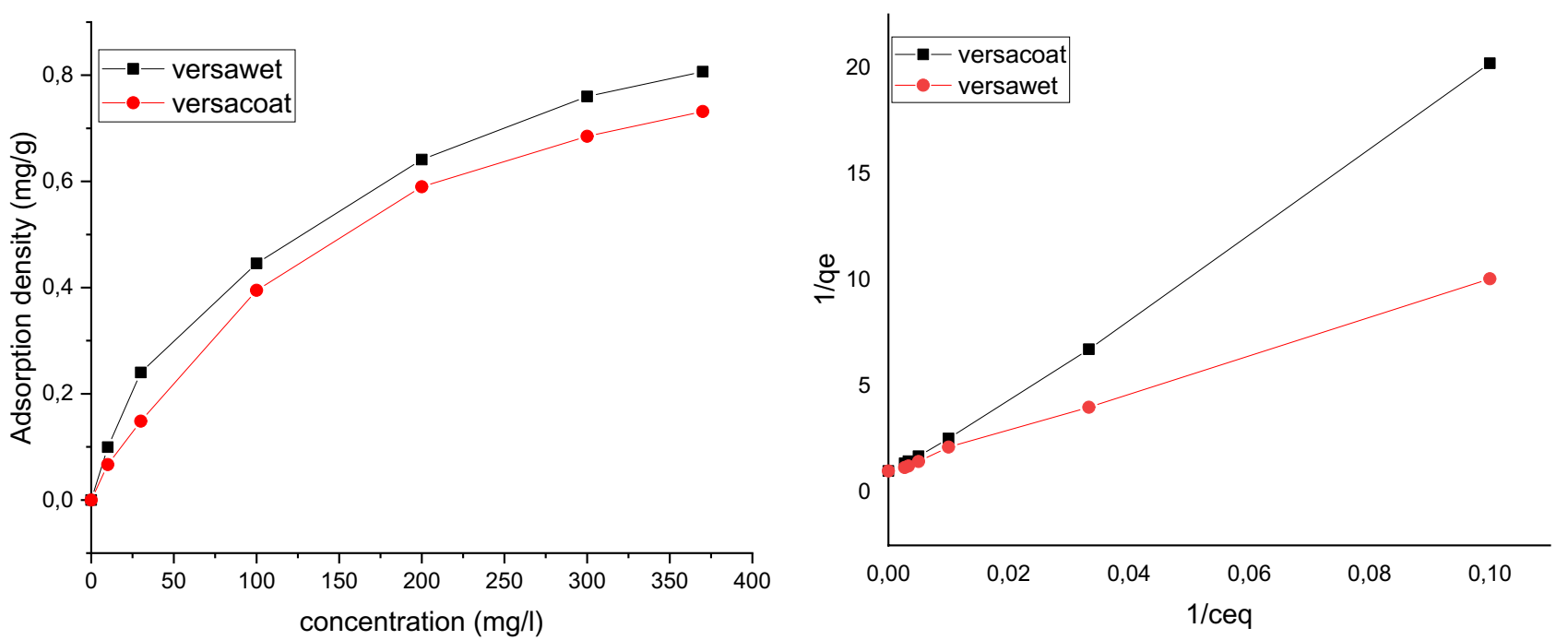

Fig. 11 Surfactant adsorption density on drilling cutting samples at $30{ }^{\circ} \mathrm{C}$ (a) with linear form of Langmuir isotherm (b)

Table 6 Langmuir isotherm parameter

\begin{tabular}{lll}
\hline Parameters & \multicolumn{2}{l}{ Adsorbent } \\
\cline { 2 - 3 } & Versawet & Versacoat \\
\hline $\mathrm{K}_{\mathrm{L}}(1 / \mathrm{mg})$ & 0.0100 & 0.0034 \\
$\mathrm{q}_{\max }(\mathrm{mg} / \mathrm{g})$ & 0.9223 & 0.8526 \\
\hline
\end{tabular}

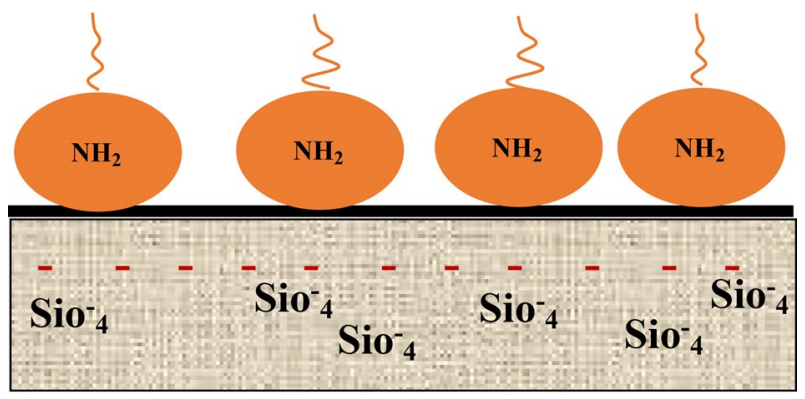

(a)

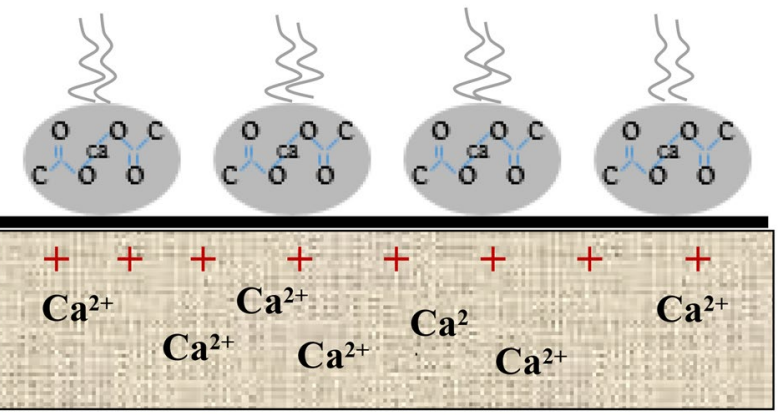

(b)

Fig. 12 Schematic of adsorption mechanism of surfactant in the surface of drilling cutting A/Versawet and B/Versacoat
- The alteration of properties is the consequence of the adsorption and retention of surfactants in the surface of drilling cutting forming a hydrophobic layer. Langmuir adsorption isotherm study showed that the interaction of Versawet and Versacoat with the powdered cutting surface from sandstone reservoir is a localized monolayer adsorption. The ability of Versawet to adsorb at liquid/ solid interfaces is high then Versacoat $\mathrm{k}_{\mathrm{L}}=0.0100$.

- The proposed mechanism for the adsorption of Versawet and Versacoat depending on the polar part of the surfactants $\mathrm{NH} 2$ for Versawet and $\mathrm{COOH}$ for Versacoat these groups have an affinity with the silanol group Sio-4 and the calcium atoms $\mathrm{Ca}$ included in the structure of the reservoir rocks successively.

- To avoid the selective adsorption of Versacoat, it is recommended to use zinc hydroxide (as an activating agent) instead of lime.

Funding Faculté des hydrocarbures, Des Énergies Renouvelables Et Des Sciences de La Terre Et de L'univers, Laboratoire Des Réservoirs Souterrains Pétroliers Gaziers Et Aquifères, Université Kasdi Merbah Ouargla, 30000 Ouargla, Algérie.

Open Access This article is licensed under a Creative Commons Attribution 4.0 International License, which permits use, sharing, adaptation, distribution and reproduction in any medium or format, as long as you give appropriate credit to the original author(s) and the source, provide a link to the Creative Commons licence, and indicate if changes were made. The images or other third party material in this article are included in the article's Creative Commons licence, unless indicated otherwise in a credit line to the material. If material is not included in the article's Creative Commons licence and your intended use is not 
permitted by statutory regulation or exceeds the permitted use, you will need to obtain permission directly from the copyright holder. To view a copy of this licence, visit http://creativecommons.org/licenses/by/4.0/.

\section{References}

Abdollah-Pour R, Torres-Verdin C, Sepehrnoori K, Nasizadeh Z (2016) Depth variation of wettability alteration during oil-base mudfiltrate invasion and corresponding effects on resistivity logs. J Petrol Sci Eng 147:593-604. https://doi.org/10.1016/j.petrol.2016. 08.029

Al-Ghouti MA, Da'ana, D. A. (2020) Guidelines for the use and interpretation of adsorption isotherm models : A review. J Hazard Mater 393:122383. https://doi.org/10.1016/j.jhazmat.2020.122383

Amirmoshiri M, Zhang L, Puerto MC, Tewari RD, Bahrim RZBK, Farajzadeh R, Hirasaki GJ, Biswal SL (2020) Role of wettability on the adsorption of an anionic surfactant on sandstone cores. Langmuir 36(36):10725-10738. https://doi.org/10.1021/acs. langmuir.0c01521

Amott E (1959) observations relating to the wettability of porous rock. Trans AIME 216(01):156-162. https://doi.org/10.2118/1167-G

Ayub A, Raza ZA, Majeed MI, Tariq MR, Irfan A (2020) Development of sustainable magnetic chitosan biosorbent beads for kinetic remediation of arsenic contaminated water. Int J Biol Macromol 163:603-617. https://doi.org/10.1016/j.ijbiomac.2020.06.287

Bagheri A, Khalili P (2017) Synergism between non-ionic and cationic surfactants in a concentration range of mixed monolayers at an air-water interface. RSC Adv 7(29):18151-18161. https://doi.org/ 10.1039/C6RA27382C

Belhaj AF, Elraies KA, Mahmood SM, Zulkifli NN, Akbari S, Hussien OS (2020) The effect of surfactant concentration, salinity, temperature, and $\mathrm{pH}$ on surfactant adsorption for chemical enhanced oil recovery : a review. J Petr Explor Prod Technol 10(1):125-137. https://doi.org/10.1007/s13202-019-0685-y

Bergane C, Hammadi L (2020) Impact of organophilic clay on rheological properties of gasoil-based drilling muds. J Petr Explor Prod Technol 10(8):3533-3540. https://doi.org/10.1007/ s13202-020-01008-x

Bishop SR (1997) The experimental investigation of formation damage due to the induced flocculation of clays within a sandstone pore structure by a high salinity brine. SPE European Formation Damage Conference. https://doi.org/10.2118/38156-MS

Butt HJ, Graf K, Kappl M (2003) Physics and chemistry of interfaces. 376

Chen J, Hirasaki GJ, Flaum M (2006) NMR wettability indices : Effect of OBM on wettability and NMR responses. J Petrol Sci Eng 52(1-4):161-171. https://doi.org/10.1016/j.petrol.2006.03.007

Civan F (2007) Reservoir formation damage : Fundamentals, modeling, assessment, and mitigation, 2nd edn. Elsevier, Gulf Professional Pub.

Civan F (2016) Reservoir formation damage : Fundamentals, modeling, assessment, and mitigation, 3rd edn. Elsevier, Gulf Professional Publishing

Craig FF (1971) The reservoir engineering aspects of waterflooding. HL Doherty Memorial Fund of AIME

He W (2021) Numerical simulation of formation damage by drilling fluid in low permeability sandstone reservoirs. 7

Hursan G, Ma SM, Valori A, Sauerer B (2018) Study of OBM Invasion on NMR Logging Mechanisms and Applications. SPE Kingdom of Saudi Arabia Annual Technical Symposium and Exhibition. SPE Kingdom of Saudi Arabia Annual Technical Symposium and Exhibition. Dammam, Saudi Arabia. https://doi.org/10.2118/ 192218-MS

Ibrahim DS, Sami NA, Balasubramanian N (2017) Effect of barite and gas oil drilling fluid additives on the reservoir rock characteristics. J Petr Explor Prod Technol 7(1):281-292. https://doi.org/10.1007/ s13202-016-0258-2

Kowalczyk I (2008) Synthesis, molecular structure and spectral properties of quaternary ammonium derivatives of 1,1-Dimethyl1,3-propylenediamine. Molecules 13(2):379-390. https://doi.org/ $10.3390 /$ molecules 13020379

Kumar A, Mandal A (2019) Critical investigation of zwitterionic surfactant for enhanced oil recovery from both sandstone and carbonate reservoirs : adsorption, wettability alteration and imbibition studies. Chem Eng Sci 209:115222. https://doi.org/10.1016/j.ces. 2019.115222

Lee B-B, Ravindra P, Chan E-S (2008) A critical review : surface and interfacial tension measurement by the drop weight method. Chem Eng Commun 195(8):889-924. https://doi.org/10.1080/00986 440801905056

Lei M, Huang W, Li N, Jia J, Li J, Wang Y, Li J (2017) The damage mechanism of oil-based drilling fluid for tight sandstone gas reservoir and its optimization. J Petr Sci Eng 158:616-625. https:// doi.org/10.1016/j.petrol.2017.09.003

Liu S, Dou X, Zeng Q, Liu J (2021) Critical parameters of the Jamin effect in a capillary tube with a contracted cross section. J Petrol Sci Eng 196:107635. https://doi.org/10.1016/j.petrol.2020.107635

McPhee C, Reed J, Zubizarreta I (2015) Core analysis: a best practice guide. Elsevier

Menezes JL (1989) The mechanism of wettability alteration due to surfactants in oil-based muds. 16

Mohammadi M, Mahani H (2020) Insights into the pore-scale mechanisms of formation damage induced by drilling fluid and its control by silica nanoparticles. Energy Fuels 34(6):6904-6919. https://doi.org/10.1021/acs.energyfuels.0c00605

Nazari Moghaddam R, Jamiolahmady M (2019) Steady-state relative permeability measurements of tight and shale rocks considering capillary end effect. Transp Porous Media 128(1):75-96. https:// doi.org/10.1007/s11242-019-01236-8

Solling T, Shahzad Kamal M, Shakil Hussain SM (2021) Surfactants in Upstream E\&P. Springer International Publishing, Switzerland. https://doi.org/10.1007/978-3-030-70026-3

Viana RB, da Silva ABF, Pimentel AS (2012) Infrared spectroscopy of anionic, cationic, and zwitterionic surfactants. Adv Phys Chem 2012:1-14. https://doi.org/10.1155/2012/903272

Xu C, Kang Y, You Z, Chen M (2016) Review on formation damage mechanisms and processes in shale gas reservoir : Known and to be known. J Nat Gas Sci Eng 36:1208-1219. https://doi.org/10. 1016/j.jngse.2016.03.096

Zhao X, Qiu Z, Sun B, Liu S, Xing X, Wang M (2019) Formation damage mechanisms associated with drilling and completion fluids for deepwater reservoirs. J Petrol Sci Eng 173:112-121. https://doi. org/10.1016/j.petrol.2018.09.09

Publisher's Note Springer Nature remains neutral with regard to jurisdictional claims in published maps and institutional affiliations. 